\title{
The legal framework of social security systems in developing countries - the example of national health insurance in Ghana
}

\author{
By Markus Kaltenborn / Lukas Lübben*
}

\begin{abstract}
For all involved, the structuring and reform of social security systems in developing countries not only faces manifold political and economic challenges, but also raises numerous legal questions. These range from the matter of which provisions of public international law and constitutional law are to be observed in the structuring of such systems, to the general legal frameworks applicable in the processes of legislation and implementation. Post-enactment, problems also arise in the monitoring and judicial enforcement of the law. The report "Social security and the rule of law", prepared 2011 in advance of the 100th Session of the International Labour Conference, clearly illustrates the different dimensions of international and national legal systems which are relevant to the structuring of a country's social security system. This article examines several such legal issues in the case of the comparatively new health insurance system in Ghana. The focus will be on questions relating to organisation and delivery which have arisen during the implementation of the Ghanaian Parliament's National Health Insurance Act 2003 and its comprehensively amended version in 2012.
\end{abstract}

\section{A. Introduction}

The establishment of national, statutory health insurance in the Republic of Ghana, under the National Health Insurance Act $2003^{1}$ has proved an ambitious and complex project. The process of enactment in 2003 revealed the continuing demand for action in public health care, and its acknowledgement in Ghanaian politics (see Section B. of this article). Nevertheless, the method of enforcement of the Act, through the National Health Insurance Scheme (NHIS), is met with significant concerns (see Section C.). In the first 10 years of the NHIS' existence,

* Markus Kaltenborn, Professor of Public Law at the Faculty of Law and Director of the Institute of Development Research and Development Politics (IEE), Ruhr University Bochum, e-mail: markus.kaltenborn@rub.de; Lukas Lübben, Research Associate at the Faculty of Law of Ruhr-University Bochum, e-mail: Lukas.luebben@rub.de. - We would like to thank Lisa Gow, LLB University of Strathclyde (Glasgow), very much for her helpful comments on this article.

1 Act 650 (2003); hereafter referred to as NHIA 2003. 
several financial ${ }^{2}$ and organisational deficiencies have become obvious. Noteworthy examples include the possible exertion of political influence on the work of the National Health Insurance Council (re-named "Board", following the 2012 amendment Act) and the administrative efficiency of the District Mutual Health Insurance Organisations (DMHIS), established under the NHIA 2003. In addition, bureaucratic obstacles are created by the coverage of those working in the informal sector of the economy. ${ }^{3}$ Such workers account for at least 70 to $75 \%$ of the entire Ghanaian labour market. ${ }^{4}$ Alongside these organisational questions, this article will address several legal problems which arise in the context of the, by and large, generous service provision offered by the Ghanaian system ${ }^{5}$, and in the enforceability of benefit claims.

\section{B. The path towards national health insurance in Ghana}

In 1957, Ghana was one of the first countries in sub-Saharan Africa to gain independence from Great Britain. Up until this point, colonial masters had attempted to establish a health care system along the lines of the British model. However, Ghanaians themselves had benefited from this system far less than the officers and employees of the British occupying forces. ${ }^{6}$ After independence was achieved, the British National Health Service provided the young state of Ghana with a template for its first tentative steps towards a health insurance scheme. First and foremost, universal healthcare was funded by tax revenues, with the remainder by donation. ${ }^{7}$ Delivery of services was free of charge and was ensured by a network

2 Cf. Sreekanth Ramachandra / William Hsiao, Ghana: Initiating Social Health Insurance, in: World Bank (ed.), Social Health Insurance for Developing Nations, Washington D.C., 2007, pp. 61-80; OECD (ed.), Development Centre Perspectives - Financing Development, Paris 2007, p. 95 ff.

3 Cf. for details Genevieve Cecilia Aryeetey et al., Identification of poor households for premium exemptions in Ghana's National Health Insurance Scheme: empirical analysis of three strategies, Tropical Medicine and International Health 15 (2010), pp. 1544-1552.

4 Oxfam / Action for Global Health, Health insurance in low-income countries. Where is the evidence that it works?, Joint NGO Briefing Paper 2008, p. 22; Robert B. A. Kuganab Lem, A Content Analysis of the Ghana National Health Insurance Scheme, Health Policy and Development 7 (2009), p. 29.

5 Agar Brugiavani / Noemi Pace, Extending Health Insurance: Effects of the National Health Insurance Scheme in Ghana, Background paper to the European Report on Development 2010, European University Institute, Florence, 2010, p. 5; http://erd.eui.eu/publications/erd-2010-publications/backgrou nd-papers/extending-health-insurance/ (last accessed on 7 October 2013).

6 Diane McIntyre et al., Beyond fragmentation and towards universal coverage: Insights from Ghana, South Africa and the United Republic of Tanzania, Bulletin of the World Health Organization 2008, p. 872; Brugiavani / Pace, note 5, p. 4.

7 McIntyre et al., note 6, p. 872; Ramachandra / Hsiao, note 2, pp. 65-66. 
of public facilities (clinics, etc). ${ }^{8}$ However, during its post-independence years, the country found itself in increasing financial difficulty, with the depletion of tax revenues that had been used to fund health care expenditure. In 1972, low service fees were imposed for the first time, for the purpose of discouraging abusive consumption of public health care services. In the mid-1980 s, these fees were significantly increased for budgetary reasons. With the introduction of co-payments ${ }^{9}$, which were designed to ensure free services for children, expectant mothers and the poor, a step was made in the direction of the "cash and carry"-system, which was officially implemented in 1992. To a certain extent, this system, which was based upon the principle of health care provision in return for immediate out-of-pocket payments ${ }^{10}$, privatised health care provision and partially released the public sector from responsibility. ${ }^{11}$ In keeping with the spirit of the times, this development illustrated that national reform measures in Ghana, as in many other countries, were clearly influenced by the structural adjustment policy of the Bretton Woods system. ${ }^{12}$ Thus, the situation was dire. It was reported that patients who were unable to pay for their own (successful) treatment, were detained in hospital until the bill had been settled by the debtor himself or by a third party. ${ }^{13}$

Since the early $1990 \mathrm{~s}$, the community-based Mutual Health Insurance Organisations have played an important role alongside established health service providers, particularly in rural areas. ${ }^{14}$ Such organisations aim to provide the population with a basic minimum level of protection against the economic consequences of disease. However, the cost of premiums and number of members differ too widely for absolute conclusions to be drawn about either the administrative structures or services ranges of such organisations. ${ }^{15}$ In any case, a key characteristic of the $\mathrm{MHO}$ is that it was arguably created as a counter-project to the "cash and carry"-system, in order to ensure cost-effective access to health care services. The funding

8 Hassan Wahab, Assessing the Implementation of Ghana's NHIS Law, 2008, p. 6, http://www.indi ana.edu/ workshop/seminars/papers/wahab_mcpaper08.pdf (last accessed on 7 October 2013); Varatharajan Durairaj / Selassi D'Almeida / Joses Kirigia, Ghana's Approach to Social Health Protection, in: WHO (ed.) World Health Report (2010) Background Paper No. 2, p. 5; http://www.wh o.int/healthsystems/topics/financing/healthreport/GhanaNo2Final.pdf (last accessed on 7 October 2013).

9 Ramachandra / Hsiao, note 2, pp. 65-66.

10 USAID (ed.), The Political Development of the Ghanaian National Health Insurance System: Lessons in Health Governance, 2007, p. 5, http://www.healthsystems2020.org/content/resource/detail/2046 / (last accessed on 7 October 2013).

11 Wahab, note 8, p. 7; Akwasi B. Assensoh / Hassan Wahab, A Historical-Cum-Political Overview of Ghana's National Health Insurance Law, African and Asian Studies 7 (2008), p. 301.

12 Cf. Kwado Konadu-Agyemang, The Best of Times and the Worst of Times: Structural Adjustment Programs and Uneven Development in Africa: The Case of Ghana, Professional Geographer 52(3) 2000, 468 (469 / 481); Assensoh / Wahab, note 11, p. 301.

13 USAID, note 10 , p. 5.

14 Ramachandra / Hsiao, note 2, pp. 65-66; Johannes P. Jütting, Health Insurance for the Poor in Developing Countries, Aldershot 2005, pp. 26-27.

15 Cf. Rob Baltussen et al., Management of mutual health organizations in Ghana, Tropical Medicine and International Health 11 (2006), pp. 655-656. 
method is based on a principle of social equity: an insured individual's personal contribution is proportionate to his income; economically weaker members are supported by way of crosssubsidisation. ${ }^{16}$ On the other hand, the quality of services cannot be regarded as up-to-date with the latest research and technological developments in conventional medicine. Rather, out of necessity, health care practice falls back on traditional medical customs which have been passed down from generation to generation; at best, recourse is made to archaic conventional medicine. ${ }^{17}$ Nevertheless, these institutions were of enormous significance for many Ghanaian citizens, precisely because the cost of medical care in conventional facilities was not affordable for the majority of the population.

The re-orientation of Ghanaian health policy was stepped up in 2000. In that year, the parliamentary election campaign was driven by the New Patriotic Party (NPP), then in opposition. The party promised to eradicate abuses in health care provision and to introduce universal health insurance for all Ghanaians, including those employed in the informal labour market, irrespective of socio-economic status. ${ }^{18}$ Not least because of this reform proposal, the NPP was able to achieve a parliamentary majority and to have one of their members elected as President. A lengthy legislative process then led to the enactment of the NHIA 2003. The decision-making process was hampered by a lack of consensus among parliamentarians and members of civil society as to the correct design and, in particular, funding method of the new health care system. A member of the Task Force, mandated by the Ghanaian Ministry of Health, concluded in his final report in 2001 that an appropriate organisational solution would be found under the auspices of a new National Health Insurance Council. This would be a combination of centralised administration for those working in the formal sector on the one hand, and local self-governing District Mutual Health Organisations, responsible for the informal economy, on the other. Finance would be secured by a National Health Insurance Fund. Besides that, it was envisaged that private health insurance companies would be admissible. Trade unions, in particular, criticised the Ministry of Health's plans to subsidise the insurance system's budget using funds from the state pension fund (Social Security and National Insurance Trust, SSNIT) ${ }^{19}$, while the previous governing party, now in opposition, also criticised plans to raise taxes in order to support the new health insurance scheme. The bureaucratic design of the new system was also the subject of criticism. Following a controversial debate lasting several months and accompanied by intense media scrutiny, legislation was finally enacted in August 2003, to establish a national health insurance fund. ${ }^{20}$ In March of the following year, the newly-established institutions began their work. The first extensive legislative amendments were achieved through the National Health Insurance (Amendment)

16 Kuganab Lem, note 4, p. 28.

17 McIntyre et al., note 6, p. 873; Kuganab Lem, note 4, pp. 28-29; Brugiavani / Pace, note 5, p. 4.

18 USAID, note 10 , p. 5; Wahab, note 8, p. 9.

19 Wahab, note 8, p. 9.

20 Act 650 (2003). 
Act, $2008^{21}$, as well as the recent National Health Insurance Act 2012. ${ }^{22}$ Important changes to the system's organisational structure have been effected through the latest reform - a centralised insurance structure has replaced the previously decentralised system.

\section{The legal framework for national health insurance in Ghana on the basis of the National Health Insurance Act 2012}

The National Health Insurance Act 2012 is subdivided into four parts:

1. Establishment of the National Health Insurance Authority and Administrative and Financial Provisions

2. Establishment of the National Health Insurance Scheme

3. Private Health Insurance Schemes

4. Adjudication and Other Provisions

The legislation is supplemented by further provisions enacted by legislative instrument in the National Health Insurance Regulations 2004. ${ }^{23}$

\section{Organisational and procedural aspects of the National Health Insurance Act}

From an organisational point of view, the National Health Insurance Authority is the primary state actor responsible for the implementation of the Act's health policy aims. To a certain extent, it can be characterised as the regulatory authority of Ghana's public health insurance scheme. The governing body of the National Health Insurance Authority is known as the Board. Further significant organisational entities include the administrative branches of the previous District Mutual Health Insurance Schemes and their private counterparts, the Private Commercial Health Insurance Schemes and Private Mutual Health Insurance Schemes. Until recently, 145 local health insurance bodies had been in operation at the district level. Currently, applications submitted by several private organisations are progressing through the registration process. Lastly, the National Health Insurance Fund plays a key role in the matter of funding.

1. The legal status of the National Health Insurance Authority

The governing body of the National Health Insurance Authority is a Board of 18 committee members. Under the NHIA 2003, which was in force until 2012, this committee was known as the National Health Insurance Council. The precise composition of the Board is regulated under section 4 of the 2012 Act. In addition to the chairperson and director, 14 members representing interest groups of various political persuasions are also appointed. Apart from representatives of various government Ministries, the Ghana Health Service and the National

21 Act 753 (2008).

22 Act 852 (2012), hereafter referred to as NHIA 2012.

23 L.I. 1809, hereafter referred to as the 2004 Regulations. 
Insurance Commission and Trust, the Board equally comprises trade union representatives, health professionals and the pharmaceutical industry. Different groups promoting various interests are also integrated into (often politically controversial) state decision-making processes. They are represented at committee level (ss 8-11, NHIA 2012) and are accorded substantial decision-making powers in both organisational and financial matters. ${ }^{24}$ Whether or not such groups are able to make a rational contribution to decision-making, in accordance with structured procedure, depends in large part on the prevailing culture of political debate. As the Board's decision-making process follows the principle of majority rule, precluding the need for absolute consensus (s 6[5], NHIA 2012), the demands of administrative efficiency will largely be satisfied. The heterogeneous composition of the Board conduces towards conflicts which would be fought more appropriately in a parliamentary forum or within a general context of public participation. These circumstances can create such a heavy burden for the work of a pluralistic committee that even simple decision-making, concerning less important matters, can be put into jeopardy.

We can find similar scenarios in older healthcare systems of certain industrialised nations. One such example is the Federal Joint Committee (Gemeinsamer Bundesausschuss) in the German healthcare system, in which representatives of health insurance companies, as well as service providers (including doctors, dentists and hospitals), play a prominent role, exercising voting rights in decisions regarding important legal questions of healthcare law. Conflict is also familiar to this committee: considering its highly heterogeneous composition, arguments appear to be simply inevitable - critics of the German approach have thus been prompted to compare the committee to a locked cage full of cats and dogs. ${ }^{25}$ However, it should be pointed out that in a democracy, it is hardly unusual for (even self-regulating) decision-making bodies to exhibit pluralistic tendencies and for their tasks to be carried out against a backdrop of political controversy. ${ }^{26}$ The Federal Joint Committee moreover faces heavy criticism on the grounds that it lacks sufficient democratic legitimacy. As it is a selfregulating body whose decisions are, to a degree, linked to considerable fundamental rights infringements, it must be considered problematic that not all of those affected by its politics are sufficiently represented in the committee. ${ }^{27}$

This democratic deficit is, however, not a feature of the Ghanaian healthcare system in its present form. A glance at the law shows that the Board acts as an arm of government, as

24 See also Section C. I. 1. a), b) and II. of this article.

25 Martin Burgi, BA-Verwaltungsrat und GKV-Bundesausschuss: Hund und Katz in Selbstverwaltung, Neue Juristische Wochenschrift (NJW) 2004, p. 1365.

26 Markus Kaltenborn, Richtliniengebung durch ministerielle Ersatzvornahme, Vierteljahresschrift für Sozialrecht (VSSR) 2000, pp. 260-261.

27 Thorsten Kingreen, Legitimation und Partizipation im Gesundheitswesen - Verfassungsrechtliche Kritik und Reform des Gemeinsamen Bundesausschusses, Neue Zeitschrift für Sozialrecht (NZS) 2007, pp. 115-117; for a different view see e.g. Ernst Hauck, Der Gemeinsame Bundesausschuss (GBA) - ein unbequemes Kind unserer Verfassungsordnung?, Neue Zeitschrift für Sozialrecht (NZS) 2010, pp. 600-612. 
far as questions of health policy are concerned. The President of the Republic of Ghana is obliged to appoint members to the Board; in the execution of this function he acts in consultation with the Council of State (Article 70, Constitution of the Republic of Ghana). As such, the Board's democratic legitimacy is derived from the presidency. Further, the Board's dependence on the President is emphasised by the relatively broad rule contained in s 5(4) NHIA 2012, which empowers the President to dismiss Board members from their posts. Beyond this, the work of the Board is under the political influence of the Ministry of Health. S 13 NHIA 2012 enables the Minister to issue binding directives of a general nature to the $\mathrm{Au}$ thority. Admittedly, the Act stresses that, as far as such directives are permissible, the Minister has at his disposal only a limited power to direct in the form of policy-making. The broad interpretative scope of this provision nonetheless leads to the conclusion that in fundamental questions relating to the Board, no decisions which contradict ministerial policy may be made. By way of contrast, when one looks at the (self-regulating) health insurance system in the Federal Republic of Germany, we can see a distinct restriction on the Federal Government's power to affect policy at the intermediate level. The most important decision-making power exercised by the Federal Joint Committee, namely, its power to enact guidelines for all integral areas of health insurance, may only be monitored by the Federal Minister for Health for the purpose of legal supervision (Article 94, Sozialgesetzbuch V). However, he is not endowed with a subject-specific supervisory power (to issue policy directives) over the Federal Joint Committee. ${ }^{28}$

The powers of the Ghanaian Board are set down indirectly by ss 4(1) and 4(3) NHIA 2012 alone, the latter stating that the Board, as a "governing body... shall ensure the proper and effective performance of the functions of the authority". The following offers some examples of its tasks, the full list of which is specified in s 3 of the Act:

- Implementation and management of the NHIS;

- Registration of NHIS members;

- Supervision of Private Health Insurance Schemes;

- Accreditation of service providers and quality controls;

- Setting of insurance rates (in agreement with the Minister of Health); and

- Administration of the National Health Insurance Fund (Appendix III).

From a legal perspective, one of the Board's most important practice areas is the admission of private health insurance schemes and the accreditation of service providers. In the following, these procedural aspects will be more closely examined.

a) Registration of Private Health Insurance Schemes and Implementation of Licensing Procedure

As per s 53 NHIA 2012, not only the nationwide National Health Insurance Scheme, but also Private Commercial Health Insurance Schemes (PCHIS) and Private Mutual Health Insu-

28 Kaltenborn, note 26, pp. 266-267. 
rance Schemes (PMHIS) are permissible organisational structures. ${ }^{29}$ These are subject to the control of the Board (ss 104-105 NHIA 2012), but do not benefit from subsidies granted by the National Health Insurance Fund. This is also stipulated by s 83 NHIA 2012 in respect of the not-for-profit PMHIS. In contrast, no provisions concerning the PCHIS, which operate as profit-driven enterprises in the open market, are to be found in the 2012 Act; it must, however, be presumed that those who drafted the legislation did not intend such schemes to be subsidised either. In sum, therefore, the legislation suggests a tripolar health insurance structure consisting of (1) public; (2) private and profit-orientated; and (3) private and non-profit schemes.

According to the statute's classification scheme, registration (the inclusion in a directory, as per s 8 of the 2004 Regulations), and licensing (meaning the permission to operate as a private health insurance scheme) are two separate legal acts. As per s 54 NHIA 2012, identical stipulations apply for both the authorisation of an entry into the register, and the granting of a licence. Thereafter, certain company law requirements must be fulfilled. S 54 provides that PMHIS should be registered in the form of a company limited by guarantee, whereas a PCHIS should be registered as a limited liability company. The relevant rules of company law are contained in the Companies Act. ${ }^{30}$ Provided the Board is satisfied that an applicant possesses sufficient qualifications, it may grant a practice licence. In this respect, it is necessary for the applicant to prove that he has qualified officers to manage the scheme (s 56[1] NHIA 2012). If the Board refuses to grant a licence, it is required as per s 59 to notify the applicant in writing, stating reasons for the decision. The Board is also empowered, on giving written notice to a scheme, to vary, revoke or impose new conditions for an existing licence (s 58[1] NHIA 2012). This stipulation is also found in $\mathrm{s} 4$ of the 2004 Regulations, according to which, the Board can require an applicant for a scheme licence to present a business plan. Additionally, licences are generally valid for two years and, on application, may be renewed for a further two years (s 57[2], NHIA 2012). As soon as a new scheme has been admitted, it must display its licence in a prominent place in public (s 68, NHIA 2012).

Even after granting a licence, the Board has a broad power to monitor and, as circumstances require, impose sanctions on schemes. For this, the general powers to manage and inspect schemes, as per ss 89(1), 104 and 105 NHIA 2012 is particularly significant. Upon the arousal of suspicion, it is also possible to summon an actuary for the purpose of investigating and cracking down upon any contraventions (ss 102-103, NHIA 2012). Additionally, the Board has the authority to revoke a licence that has already been granted and to appoint a management team in the place of the original operator, in order to ensure the interim management of the scheme (ss 60-61, NHIA 2012). This power of rescission is particularly relevant in cases where the applicant for a licence has committed fraud in the fulfillment of the licence requirements; where the scheme is not administered in accordance with good practice

29 For a discussion of the role of the private sector in health systems of developing countries see Jane Doherty / Diane McIntyre, Addressing the failings of public health systems: Should the private sector be an instrument of choice?, in: Rebecca Surender / Robert Walker (eds.), Social policy in a developing world. Cheltenham, 2013, p. 101.

30 Act 179 (1963). 
and procedure; or where the scheme is financially unable to operate (s 60[1], NHIA 2012). Before the decision to revoke a licence is made, responsible members of the scheme are to be given an opportunity to make representations (s 60[2], NHIA 2012). All decisions of the Board, in respect of the granting, revocation or suspension of licences, are to be published in the Ghanaian Gazette and specified national newspapers (s 67, NHIA 2012).

All in all, one can view the design of the licensing procedure as expedient and strict. A positive overall picture is only tainted by the requirement that scheme licences must be renewed every two years. Redundant administrative work is created by the carrying out of licensing procedure according to this schedule. In this respect, another comparison with other health insurance systems could deliver worthwhile tips, as these often allow for regulatory bodies to grant open-ended licences to both private insurance providers and public health insurance companies (for example, in Germany this can be done on the basis of Article 6 Versicherungsaufsichtsgesetz ${ }^{31}$, as well as Articles 148, 153, 158, 168 and 170 of Sozialgesetzbuch $\mathrm{V}^{32}$ ). In Ghana, the Board has extensive powers of supervision and sanction which, appropriately construed, allow for an efficient - preventative as well as repressive - control of certain schemes. As such, it would appear to be a sensible idea to re-shape the licensing procedure and eschew the regular repetition of licence renewal.

b) The granting of credentials to service providers

In regard to the admission of health care providers into the Ghanaian health insurance system, the NHIA 2012 is limited to a stipulation of certification and accreditation obligations (ss 32 and 100) and a reference to the relevant executive regulations. First of all, s 22 of the 2004 Regulations contains a list of institutions which are eligible for the granting of credentials. This list includes hospitals, care homes, maternity homes, health centres and pharmacies of various types. In addition, this provision contains an escape clause empowering the Authority (respectiveley accordimg to the new law the Board) with a certain discretion to expand the list of facilities eligible to receive credentials. The approval procedure is broken down into the testing of: (1) the performance of the applicant seeking credentials and (2) the compliance with special standards applicable certain special types of facility. The general criteria specified in s 23 of the 2004 Regulations, according to which the qualifications of the applicant are be examined and ascertained, include evidence that the applicant has completed a period of six months' high quality service. In addition, the applicant should have trained staff, technically up-to-date equipment and adequate space available. Finally s/he must make a declaration that $\mathrm{s} /$ he agrees to cooperate with the supervisory bodies in the carrying out of quality control and other administrative obligations, such as book-keeping. Special performance-related requirements are specified in s 24 of the 2004 Regulations in respect of the granting of credentials to hospitals (for example, the need to obtain an additional acknowledgement from the Ministry

31 Insurance Supervision Law.

32 Social Security Code. 
of Health). All those who practise a health-related occupation in such an accredited facility are, according to s 26 of the 2004 Regulations, subject to specific performance-related requirements; here, a reference is made to the respective laws and standards applicable to those working in health professions.

The initial accreditation period for a service provider is limited to five years; subsequently, a two-year renewal can be made on application (s 23[3], 2004 Regulations). The Authority (respectively now the Board) may examine any and all of the accreditations at any time (s 34, 2004 Regulations). Supervision of particular service providers is carried out in cooperation with the health insurance schemes (s 35[2], 2004 Regulations). According to s 35, the aim of these quality controls is to prevent "gross and inexcusable" deviations from the service-related standards set during the course of the accreditation procedure. Additionally, the use of counterfeit or adulterated medication, or the prescription of drugs which have not been authorised in the National Health Insurance Drug List, is supposed to be counteracted here. At least, as far as law is concerned, the means exist to rebuke any reported misdeeds carried out in the process of health care provision.

2. From the decentralised approach of the District Mutual Health Insurance Schemes (under the NHIA 2003) to the unitary insurance scheme under the NHIA 2012

Until 2012, the overall administrative structure of the NHIS was characterised by a general policy of decentralisation. ${ }^{33}$ Although this approach has been abandoned in the legislative reform of 2012, it is worthwhile to take a look at the previous organisational structures which shaped the health insurance system in Ghana over several years and constituted, at times, a model for health care systems in other countries. According to s 29 NHIA 2003, it was required that a DMHIS should be established in every Ghanaian district. The DMHIS were conceived of as autonomous bodies, which would, nevertheless, be subject to the oversight of the $\mathrm{Au}$ thority (s 23, NHIA 2003). When there was no DMHIS in a particular district, a district assembly was supposed to locate suitable initiators for this purpose (s 29[2], NHIA 2003). In principle, membership of a DMHIS has been mandatory for all Ghanaian citizens; however, those who were already insured privately, either in a PCHIS or PMHIS, or were members of the military service or police, were exempt from this compulsory membership. Nevertheless, it has been shown that the desired goal of universal insurance coverage had still not been achieved by the system of compulsory membership. More recent official estimates suggest that the NHIS has a total active membership of 8.2 million representing only $33 \%$ of the population $^{34}$; according to data from NGOs, which have taken a critical approach to the

33 Ebenezer Appiah-Denkyira / Alex Preker, Reaching the Poor in Ghana with National Health Insurance - An Experience from the Districts of the Eastern Region of Ghana, in: Jens Holst / Assia Brandrup-Lukanow (eds.), Extending social protection in health: Developing countries' experiences, lessons learnt and recommendations, Frankfurt a.M., 2007, pp. 73-81.

34 National Health Insurance Authority, Annual Report 2011, p. 10; http://www.nhis.gov.gh/files/ann ualreport2011.pdf (last accessed on 7 October 2013). 
Ghanaian health care system, the actual number of those who are insured is even smaller than the official estimates. ${ }^{35}$ As in many other countries, the inclusion of the informal sector has proved to be particularly difficult. ${ }^{36}$ The members of this demographic group are easily able to exclude themselves from registration, while they simply ignore their statutory duty to pay obligatory contribution costs (s 31[2] NHIA 2003). In contrast, the registration of those active in the formal economy is undoubtedly easier to manage, because the membership costs, as well as contributions to the state pension fund, are paid through payroll deductions and recourse can be made to already available data.

The DMHIS are charged with continuous administrative tasks, namely those concerning billing for services, the processing of membership applications, the presentation of insurance cards and the collection of membership fees. ${ }^{37}$ In this context, the carrying-out of a means test, according to s 38 NHIA 2003, is also worth mentioning. This process is designed to ascertain which individuals who, owing to their socio-economic status, should be exempted from payment of the compulsory contributions. However, the Act contains no further statements as to the applicable criteria for the granting of such an exemption. In this respect, in $\mathrm{s}$ 38 of the 2003 statute, it was specified that a means test of this type should be stipulated by the Ministry of Health on the recommendation of the National Health Insurance Council. More detailed guidelines are to be found in s 58 of the 2004 Regulations. The Ministry of Finance is also a key actor in this context; in consultation with the NHIC, it allocates the budget for the support of those entitled to relief (s 38[5], NHIA 2003). On this basis, one can assume that this support was sometimes set lower and sometimes higher, corresponding with the income thresholds which changed, depending on the financial situation at the time. The schemes were obliged to keep lists of all of those who were exempt from paying the compulsory contributions, and to forward these to the NHIC for examination. When discrepancies arose in the assessment of an individual as "needy" or "not needy", the members of the particular scheme were able to arrange an examination through the District Health Complaint

35 Oxfam, Achieving a Shared Goal: Free Universal Health Care in Ghana, 2011, pp. 23-25, http://w ww.oxfam.org/sites/www.oxfam.org/files/rr-achieving-shared-goal-healthcare-ghana-090311-en.p df (last accessed on 7 October 2013). For this debate see also World Health Organization / Providing for Health (P4H) initiative, Success Stories of Health Financing Reforms for Universal Coverage. Ghana: coverage expansion through political commitment and innovative policy choices, 2011, p. 4, http://www.who.int/providingforhealth/PH4_Ghana_success_story.pdf (last accessed on 7 October 2013).

36 Cf. Juan R. de Laiglesia, Coverage gaps in social protection: What role for institutional innovations, Paris, OECD Development Centre, 2011, http://www.oecd.org/dev/perspectivesonglobaldevelopm ent/47588850.pdf (last accessed on 7 October 2013); Nicola Smit, Institutional framework, legal instruments and legal techniques relating to the promotion of access to social security to informal sector workers - An international perspective (ILO), in: Ulrich Becker / Marius Olivier (eds.), Access to social security for non-citizens and informal sector workers. An International, South African and German Perspective, Stellenbosch 2008, pp. 193-208. See also the Report of the Independent Expert on the question of human rights and extreme poverty, Magdalena Sepúlveda Carmona, 17 March 2011, UN-Doc. A/HRC/17/34, para. 74.

37 Ramachandra/Hsaio, note 2, p. 70. 
Committee (s 58[6], 2004 Regulations). All in all, one must assume that the means test criteria in previous practice were very strictly set out. In 2008 , only $1 \%$ of the Ghanaian population possessed this status, despite the fact that $28 \%$ of the overall population were living below the poverty line. ${ }^{38}$

The DMHIS were supposed to fulfill the provisions of s 54 NHIA 2003 and s 11 of the 2004 Regulations which stipulated the existence of a governing body for each scheme, in the form of an executive board, to whom between 7 and 15 members (including two women) of the scheme were to belong. No detailed rules regarding the hiring of executive board members were established in the provisions. Instead, s 3(I) (f) of the 2004 Regulations gave the schemes the discretion to decide whether the allocation of positions should be determined by appointment or by vote, and how the particular procedure should be designed. S 54 NHIA 2003 lists the responsibilities of the executive board. Accordingly, the board was responsible for both the scheme's general policy orientation and for the hiring of staff. In addition, the schemes were granted only limited autonomy in respect of their internal organisational structure. S 13 of the 2004 Regulations prescribes the appointment of a scheme manager, as well as the lineup of further managerial positions. In this respect, rather detailed provisions have been set out, concerning the professional and personal requirements of the office-holders; additional stipulations pertaining to those employed by the DHMIS were found in s 59 NHIA 2003. In comparison to other decentralised health insurance systems, such a restricted power over staff is by no means unusual; one such example is found in the corresponding provisions in Article 35 a of the German Sozialgesetzbuch IV, concerning executive board members of health insurance companies. One of the biggest problems faced by the DMHIS must surely be the gathering of sufficient numbers of qualified employees who possess adequate leadership and administrative skills. ${ }^{39}$

Given the geographical proximity of the DMHIS to both insured individuals and service providers, the principle of decentralisation, which had long been pursued in Ghana, has undoubtedly had its advantages. Nevertheless, there are also strong arguments speaking in favour of the exercise of specific scheme tasks at the supra-regional level. Thus, for reasons of administrative efficiency, it would appear sensible to establish a smaller number of regional centres at which comprehensive, district-orientated tasks could be concentrated. Furthermore, according to the principle of "risk-pooling", a closer intertwining of individual schemes would be advisable. ${ }^{40}$ However, the Ghanian legislature has in fact gone further: As of now, the

38 Sophie Witter / Betha Garshong, Something old or something new? Social Health Insurance in Ghana, BMC International Health and Human Rights 9 (2009), p. 26; Jenna Dixon, Financing national health insurance in Ghana, AfricaPortal, Backgrounder no. 8 (July 2011), p. 5, http://www.africaportal.or g/articles/2011/07/13/financing-national-health-insurance-ghana (last accessed on 7 October 2013).

39 Kuganab Lem, note 4, p. 28; Oxfam, note 35, p. 31.

40 Cf. also Raymand A. Atuguba, The right to health in Ghana: healthcare, human rights, and politics, in: Josè M. Zuniga / Stephen P. Marks / Lawrence O. Gostin (eds.), Advancing the Human Right to Health, Oxford, 2013, p. 106; George Schieber / Cheryl Cashin / Karima Saleh / Rouselle Lavado, Health Financing in Ghana, World Bank, Washington D.C., 2012, pp. 19, 22, 93, 99. 
legislative reform of 2012 provides for a unitary (standard) National Health Insurance Scheme alongside the private schemes (s 26[1], NHIA 2012). ${ }^{41}$ Each resident of Ghana shall belong to the National Health Insurance Scheme unless s/he is member of a private health insurance scheme an (s 27[1-2] NHIA 2012). Employers have to ensure that their employees are registered under the National Health Insurance Scheme (s 27[12] NHIA 2012). It is still too early to predict whether this strategy to achieve universal health coverage will be really successful, but the reform shows the Ghanaian government's firm commitment to get closer to this ideal by using the "classic" instrument of social insurance in the health sector. ${ }^{42}$

\section{The funding of Ghanaian health insurance}

Until now, the NHIS has been funded substantially by tax revenues, thereby more closely resembling a public health service than a private health insurance scheme. For the specific purpose of generating revenues in order to support those who have been designated as "needy", the Ghanaian legislator set down a National Health Insurance Levy (2.5\% charged on the supply of goods and services, s 47, NHIA 2003). In the first years of its existence, $70-75 \%$ of the new health insurance system was financed from this source. ${ }^{43}$ The remaining $20-25 \%$ of the budget consists of contributions paid by those employed in the formal economy: $2.5 \%$ is taken from payroll deductions (which amount to $17.5 \%$ of salary), paid by the formal labour force towards the Social Security and Pensions Scheme Fund, along with tax revenues and state subsidies provided by the National Health Insurance Fund (s 41, NHIA 2012). What is interesting in this context is the rule contained in the previous provision, s 78(3) NHIA 2003, according to which, the contributions were to be made without prejudice to the benefits due to contributors under the Social Security Pensions Scheme. Because of this, critics had accused the Ghanaian government of bowing down under pressure exerted by trade unions and, to a certain extent, ensuring free health insurance for those employed in the formal sector. This rule has been omitted in the 2012 Act.

What is less astonishing is that the informal sector pays only a 5\% stake towards the overall funding of the Ghanaian health insurance system, despite the fact that it comprises approximately $80 \%$ of the entire labour force. A progressive rate of calculation of premiums is prescribed, comprising of six levels from "core poor" (exempt from mandatory contributions ${ }^{44}$ ),

41 See also the transitional provisions in s. 112 NHIA 2012.

42 See also the recommendations of the World Bank experts in Schieber et al., note 40, p. 154.

43 Witter / Garshong, note 38, p. 24.

44 Cf. in this context Caroline Jehu-Appiah et al., Efficiency, equity and feasibility of strategies to identify the poor: An application to premium exemptions under National Health Insurance in Ghana, Health Policy 95 (2010), p. 166. 
to "very poor / poor", to "middle income", to "rich / very rich". ${ }^{45}$ However, the NHIA does not specify any numerical figures corresponding to income thresholds for these categories. Instead, persons wishing to be allocated to a particular category evaluate their own socioeconomic status. Thus, the individual's personal circumstances are broadly outlined in the form of six factors. For example, the group designated "core poor" are defined as "adults who are unemployed and who do not receive any identifiable and constant support from elsewhere for survival", while the "very rich" are described as "adults who are able to meet their needs and most of their wants". Approximately $99 \%$ of those who registered themselves in this way placed themselves in the groups "very poor" or "poor". Both groups pay an annual premium of the equivalent to 3 EUR. Alongside the "core poor" of the informal labour market, other groups are exempted from paying contributions. These include pensioners and those over the age of 70, as well as minors (since the amendments made in the 2012 Act, this applies regardless of whether a minor's parents are contributors) and those who are generally described as "needy" (s 29 NHIA 2012). For some time, the possibility of a departure from annual premiums, towards the introduction of one-time contributions or registration fees, which would be valid for the duration of a person's lifetime, has been under discussion.

\section{The range of services available under the health insurance system}

The central purpose of each health protection system is to secure the supply of the population with basic healthcare services. In many systems the details of the range of services are not part of parliamentary acts but they are laid down in administrative instruments ${ }^{46}$ - also in Ghana: In ss 30, 94 NHIA 2012 the Minister of Health has been empowered to set down, by legislative instrument and in consultation with the Board, a list of health care benefits. S 19(1) of the 2004 Regulations makes reference to Appendix II, the first paragraph of which defines a conclusive list of mandatory "minimum health care benefits" which must be provided by the district schemes. The second paragraph contains a so-called "exclusion list" (see also s 20 of the 2004 Regulations) of non-mandatory services. Next, s 19(2) of the Regulations grants schemes the option to broaden their range of services. However, due to the accompanying rise in premium costs, such an extension can only be achieved with the agreement of the scheme members (s 19[2]), and is subject to the approval by the Board (s 19[3]). Provision of services to a patient is through accredited facilities, akin to what is also known (e.g. in Germany) as the principle of benefits in kind (cf. s 38[1]). According to the episode of care system run by the district schemes, the reimbursement of costs to service providers must be completed within

45 Kuganab Lem, note 4, p. 29. It should however be noticed that there have been problems in the application of the income classification categories, as in practice several district schemes apply flat rates for premium payment across categories; see Alex Addae-Korankye, Challenges of Financing Health Care in Ghana: The Case of National Health Insurance Scheme (NHIS), International Journal of Asian Social Science 2013, p. 521.

46 For example, in Germany the Federal Joint Committee (see C. I. 1) is responsible for adopting guidelines which contain the details of the benefits catalogue (Art. 92 Sozialgesetzbuch V). 
one month (s 38[1]). In a pilot scheme in the Ashanti region, the Managed Care model, which is already in operation in other health care systems, has been tested. Except in cases of severe emergency, the first port of call for an insured person is a primary health care provider, which is the functinoal equivalent of a general medical practitioner. From there, a patient may be transferred to specialists when necessary (the so-called "pilot model" ${ }^{\text {") }}$ ). In reality, however, several barriers exist, hindering the effective access of insured persons to health care services. In particular, rural and poor regions in Ghana suffer from an acute lack of service providers. ${ }^{48}$

Furthermore, s 19(4) of the 2004 Regulations lists the "free public health services", which are available to all Ghanaian citizens, irrespective of membership of a publicy-funded District Scheme. Incidentally, no mention is made in the NHIA of the relationship between these services and the Board, and how they can be appropriately integrated into the new system. Particular examples of free public health services in this category include, among others, vaccinations, family planning advice and support, the treatment of psychological illness, tuberculosis, Buruli ulcers, river blindness, conjunctivitis and HIV tests.

The package of services is set down as a numerus clausus in an Appendix to the legislative instrument and treatment is offered in the form of both in- and out-patient care. ${ }^{49}$ Additionally, a distinction is drawn between dental and eye care and prenatal examinations and emergency treatment. The intention of the Ghanaian legislator was to facilitate the development of cures for the ten most common diseases in the country. ${ }^{50}$ Nevertheless, the scope of available services has been the subject of criticism. ${ }^{51}$ Complaints have been made that insufficient calculations in respect of the financing structure have been made, in view of future earnings. Critics say that this omission, which was made at the planning stage, inevitably leads to an inefficient and unsuitable deployment of available means. Instead, it would have been preferable during the NHIS' building phase to ignore out-patient care, in order to minimise costs, and to tackle the most serious diseases exclusively with hospital treatment. Additionally, the re-introduction of co-payments has been under discussion. ${ }^{52}$ In this way, another revenue source would be developed, thereby creating an effective means against abusive benefit claims. Apart from that, reference to the example of Tanzania has been made: according to Tanzanian law, both in- and out-patient care is provided for, but in contrast to Ghana, a rigid "pay-out limit" per patient has been implemented, in order to discourage needless benefit claims. ${ }^{53}$ The fact that

47 See Ramachandra / Hsiao, note 2, p. 71.

48 Cf. Appiah-Denkyira/Preker, note 33, pp. 79-80.

49 See also ss 33, 34 NHIA 2012, and for more details the National Health Insurance Scheme Medicines List (http://www.nhis.gov.gh/MedList.aspx, last accessed on 7 October 2013) as well as the National Health Insurance Scheme Service List (cf. http://www.nhis.gov.gh/benefits.aspx, last accessed on 7 October 2013).

50 Kuganab Lem, note 4, p. 30.

51 Appiah-Denkyira/Preker, note 33, p. 79.

52 Ibid.

53 Kuganab Lem, note 4, p. 31. 
such a rationing of health care services contributes to the reduction of costs and makes economic sense is virtually indisputable. Nevertheless, it raises the question of whether such a method woild be still based on the type of broad social consensus which, in Ghana, was expressed through parliamentary and presidential elections whose campaigns had focused heavily on the introduction of the NHIS.

\section{$I V$. Dispute resolution and legal protection in the Ghanaian health insurance system}

The system of dispute resolution in the Ghanaian health insurance system was also reformed in 2012. In this context, the key norm of the old legal provisions were contained in s 2(2)(g) of the NHIA 2003. According to this, the Authority was obliged to create a dispute resolution mechanism for resolving complaints by schemes, members of schemes and healthcare providers. Thereafter, s 8 NHIA 2003 provided for the creation of a Health Complaint Committee (HCC). The HCC was located at the Authority and, from an organisational perspective, was set up as a type of committee of the NHIC. In contrast to other committees of the NHIC, posts within the HCC could, according to the NHIC's discretion, be occupied by external members. S 8(2) NHIA 2003 stipulated that the chairperson of the HCC should be a member of the NHIC. The HCC had been allocated the task of hearing and resolving complaints concerning the NHIS (s $8[3$ a]) NHIA 2003). The procedure and the sanctions at the committee's disposal should be further consolidated in the form of regulations. S 8(4) NHIA 2003 stated that " $[\mathrm{t}]$ he HCC shall be decentralized and established in every district office of the Authority". S 43 designates the decentralised offices of the HCC as "District HCC". The 2003 Act did not bestow any legal decision-making power to these Disrict HCCs, which instead functioned as a mediator in the dispute. Only after it was established that no settlement could be reached on the District Scheme level, or that the Scheme had not taken any action within 60 days of the application, would an appeal to the HCC be admissible (s 43[5] of the 2003 Act and s 44 of the 2004 Regulations).

The new law, following the 2012 amendment, now provides for the establishment of an Adjudication Committee, which consits of a chairperson - a retired Justice of the Superior Courts of Judicature - and several representatives of health sector institutions and interest groups (s 106 [1-2], NHIA 2012). The task of this new Committee is to hear and determine complaints made by a member of the scheme or by healthcare providers under the scheme; complaints can also referred to it by the Board (s 106 [3], NHIA 2012). Altough the details of the procedure for the resolution of conflicts are still not regulated in the parliamentary act but have to be specified in the form of regulations (s 106 [4], NHIA 2012), the differences of the new law compared with the NHIA 2003 should not be underestimated: Both the composition of members and the organizational status of the Adjudication Committee illustrate that the Ghanaian legislator tries to enhance legal protection in the health sector. Proponents of a rights-based approach certainly will welcome this development as it is - from a human rights perspective - of crucial importance that programme administrators, health care providers and other people whose actions might have an impact on the implementation of the health pro- 
tection schemes can be held accountable when their decisions affect the right to social security or the right to health. ${ }^{54}$

\section{Conclusion}

In allusion to the banking and economic crises of 2009 and 2010, the NHIS has been described as "too big to fail". ${ }^{55}$ This judgment, made ostensibly on the basis of health economics in general and the sustainability of the funding structure in particular, can also be buttressed by the above legal considerations. All in all, the appropriate implementation of the NHIS project is a key factor in the successful tackling of poverty in Ghana. However, the existence of certain problems in policy implementation still gives rise to the need for amendments. A particular cause for worry is given by reports claiming that the central goal of the NHIA - the abolition of the "cash and carry"-system - has still not been completely achieved, even after several years of the NHIS' existence. ${ }^{56}$ The numerous and justifiably deplored out-of-pocket expenditures have not yet been completely overcome, and continue to present a considerable barrier against effective access to medical care, especially for the poorest members of the population. Some of the organizational problems - mainly the lack of clear delineation of collective and institutional competences between particular actors in the different schemes ${ }^{57}$ - might have been solved by the new institutional framework of the NHIA 2012. But it remains to be seen whether the more centralized approach according to the amendments made in the 2012 Act will actually provide the basis for a sufficient degree of efficiency and coherence - and last but not least also of accountability - in the governance structure of the NHIS.

54 Cf. (with regard to the right to social security) Magdalena Sepúlveda / Carly Nyst, The Human Rights Approach to Social Protection, Helsinki 2012, p. 60, http://www.ohchr.org/Documents/Issues/EPo verty/HumanRightsApproachToSocialProtection.pdf (last accessed on 7 October 2013); see also Markus Kaltenborn, The Human Rights-Based Approach to Social Protection, in: Katja Bender / Markus Kaltenborn / Christian Pfleiderer (eds.), Social Protection in Developing Countries: Reforming Systems, Abingdon 2013, pp. 56-57.

55 Witter / Garshong, note 38, p. 31.

56 Brugiavani/Pace, note 5, p. 12.

57 Ramachandra/Hsaio, note 2, pp. 71-72. 